\title{
Research on the Integration and Development of WDC and WDSF
}

\author{
Qi Daobao \\ Institute of physical education, Zaozhuang University
}

\begin{abstract}
With literature review, expert interviews, logical induction and deduction, this research analyzes the development history of WDC and WDSF, dancer demands, evaluation rules and development ideas, and proposes that the integration and development of the two associations can be effectively unified in the aspects of technical skills, teaching materials and future development direction of sports dance, thus providing uniform standards for dance lovers and standardizing International Standard Dance.
\end{abstract}

Keywords-WDC; WDSF; Sports dance; International Standard Dance; Integration and development

\section{INTRODUCTION}

WDC and WDSF are established to provide services and help for dancers. They have made great achievements in teacher training, referee training, the compilation of textbooks, the induction and summary of motion techniques, and the planning of events. Also, they have made great contributions to the development and promotion of sports dance. WDC executives believe that the international standard dance should develop towards the essence of dance, express people's feelings and thoughts through dance, and advocate the artistic nature of dance. However, WDSF executors believe that sports dance should be competitive, and hope that it will become a sport accepted by the Olympic Committee in the future, so that more people can participate in it to grow and develop. For dancers, learning to dance or to engage in dance is rooted in the love of the dance itself, but a number of issues such as which organization to develop and grow, the direction of development of the dance, and how to form a dance style are presented. Then the author believes that the integration and development of the two associations can be carried out from the four aspects such as the development history of WDC and WDSF, dancer demands, evaluation rules and development ideas.

\section{RESEARCH STATUS OF WDC AND WDSF INTEGRATION AND DEVELOPMENT AND RESEARCH METHODS ADOPTED IN THIS TEXT}

\section{A. Research Status}

In 2016, Liu Hu pointed out the influence of the change of WDSF's scoring system on the motion technique and dance style of Latin dancers in the Change Characteristics of WDSF Dance Sport Scoring System and its Influence on the Motion Techniques of World Elite Latin Dancers. Sun Lihong and Li Yuwei respectively published Research on the Differences of the Code of Points of Competition between WDC and WDSF and the Evolution of the World Sports dance Federation (WDSF) competition rules through the research and study of sports dance rules. The research of Sun and $\mathrm{Li}$ shows that WDC and WDSF can practice "win-win" in mutual learning. In the Analysis of the WDSF Sports Dance Judging System, Huang Chengcheng pointed out that improving the transparency of sports dance competition enhances the objectivity of the score, but the research on the integration and development of WDC and WDSF is still the tip of the iceberg. Therefore, the integration and development of WDC and WDSF needs to be further studied.

\section{B. Research Methods}

\section{1) Literature Review}

With the method of literature Review, 11 articles about WDC and WDSF were retrieved in CNKI and Wanfang Database. There is almost no research on the integration and development between WDC and WDSF by sorting out the viewpoints and information in the literature and carrying out logical induction and deductive analysis on its contents.

\section{2) Interview Method}

Through visiting famous scholars and dance experts at home and abroad, and making calls to the relevant functional departments, the consultation and exchanges concerning the integration and development between WDC and WDSF were pushed forward.

\section{RESULTS AND ANALYSIS}

\section{A. The history and interfluve between WDC and WDSF}

The World Dance Council (WDC), whose predecessor [1] is The International Ballroom Dance Council, is the earliest organization in the world to regulate sports dance. The World Sports dance Federation (WDSF), originally established as the International Council of Amateur Dancers (ICAD), was founded in 1957 and in 1990 adopted the name of the International Sports dance Federation (IDSF). At the beginning of the organization, it was an international sports dance amateur organization, and at the same time transported professional players for WDC. With the subsequent development and market conflicts, WDC and IDSF parted ways in 2007. In 2011, in order to emphasize the global nature of the organization, it was renamed WDSF and is headquartered in Germany [2]. The World Sports dance Federation currently controls $95 \%$ of the world's sports dance 
competitions, which mainly include world, continent and regional championships, cups, and world open tournaments [3]. Due to the WDSF's courage to develop new ideas and the need for multi-party cooperation and win-win results, there are more and more participants, and its scale becomes larger and larger with the popularity and influence increasing. For WDC, based on its own understanding of the international standard dance, the project is relatively conservative and slow, so the WDSF is better than WDC in the promotion of the project.

From the development of the two associations, WDSF initially attached to WDC and served WDC. Due to the thinking innovation of WDSF and its dare to break through the status quo, it attracted the attention of the world people to sports dance with the help of the Olympics and won the authority of sports dance. As the two are guiding the development of sports dance and international standard dance, they are originally a family, just like the relationship between "elder brother" and "younger brother". And the present situation is not conducive to the development of the project. At this time, only when "parents" come out to mediate will the two sides mutually benefit and develop together. The author believes that the integration of the two major associations must first establish a unified organization, and the relevant departments of the government of the origin should make recommendations and give policy support to guide them, so that the association can be rationally reorganized. Let the international standard dance become a true unity and achieve the ideal effect of " $1+1>2$ ".

\section{B. The trend and fusion between WDC and WDSF}

\section{1) Dancer Demands}

International standard dance includes two major categories: standard dance series and Latin dance series. As it combines the connotation of cultural entertainment and the dual characteristics of sports competition, as well as the strong performance and craftsmanship, the Western dance industry calls it "sports dance"[4]. Sports dance is developing rapidly all over the world, and even the less affluent villages and towns have studios for technical training in this area. This shows that more and more people participate in sports dance learning with great enthusiasm. For office workers, learning sports dance can exercise the body, improve temperament, and increase interpersonal communication. For students, learning it can become a profession, have a skill, and become a stepping stone in progression; for retired people, learning it can cultivate sentiment and self-cultivation. These people are dancers. In their primary learning process, they will not find the differences in technical skills of the motions and the concept of choreography. But after deeper learning, the dancers will find many problems, such as the same motion taught by varied teachers will have many versions. When dancers communicate with each other, they always think their motions are standard and deny others, which creates a very disharmonious situation. Sometimes the mouth does not speak of the heart, just like WDC and WDSF launch a series of teaching materials, events, but each association has its own champion, and the respective association also restricts the dancers not to participate in the opponent's competition, which makes the dancers very distressed. The exchanges between the dancers are more conducive to the development of the project. And let each other's champion compete to select a unique one, which will bring dancers a consensus and a sense of identity. It also can encourage dancers to strive for the goal of the champion rather than standing aimlessly. It also allows the hesitant dancers or practitioners to have the courage and confidence to continue. The author believes that the movements can be varied, but the principles of dance and motions must be consistent, and a unified basic footwork is given to mark the dancers, which helps them keep a unified ruler in mind. Then WDC and WDSF technical experts reached a consensus on the technical principles, forming a teaching material for teacher training, examination content and basic training.

\section{2) Convergence of Evaluation Rules}

The evaluation rules of WDC always follow the traditional scoring standards, including six aspects: basic technology, musical expressive force, dance style, motion arrangement, onthe-spot play and field effect. WDC emphasizes the artistry of dance, which cannot be seen or touched, but can only be felt. Perhaps this is the characteristics of sports dance itself. So, for the dancers who can enter the final circle, the basic skills of dance and the performance of music are quite excellent. If judged by the public, every dancer can be the champion. WDC judgers are bound to be skilled in professional origin, but they also have the nature of human nature. They may be strongly subjective in the process of judging and scoring, which will have a negative impact on the evaluation of the dance because of personal preferences, emotions, personal factors and so on.

The WDSF scoring system mainly includes the following four aspects. 1. TQ Technical quality includes posture, posture holding, foot movement, Latin movement, basic movement, preparation - movement - reduction, rotation and rotation, separation movement - coordinated movement, skillful dance steps, dynamic changes, lines and ductile lines. 2. MM Movements to music include rhythm, drag rhythm, beat rhythm, music structure.3. PS Partnering skills include body communication, super balance, counterbalance, holding, falling, space use, synchronization, stability and consistency. 4. CP Choreography and presentation include structure and composition, non-verbal communication, location and venue utilization, style characteristics, energy use, and atmosphere.

The WDC and WDSF rules can be effectively integrated. The basic technology in the first rule are harmonious with the technical quality in posture, balance, foot motion or foot movement; the second rule of music expression are harmonious and unified with music application in the rhythm, music structure or style; the third is different. WDSF emphasizes the cooperation between partners while WDC emphasizes dance style and dancer's personal style; WDC's fourth, fifth and sixth: dance choreography, on-the-spot play and game effect are also roughly the same as WDSF Article 4: routines and performances. In general, the WDSF emphasizes the competitive or sporty nature of dance. It requires the dancers' movements to move toward the spirit of sports - faster, higher, and farther, thus bringing the effect more passionate and more exciting. Therefore, the integration of WDC and WDSF has completely bases and conditions, so the two can merge the same indicators and develop and combine the different. This can effectively avoid the subjectivity of WDC, and the 
stereotype of WDSF, which innovates sports dance evaluation rules.

\section{3) Integration of Development Concepts}

WDC's development philosophy: 1. Develop the international standard dance program, let more people participate in it, so that people can exercise, cultivate selfcultivation, and enhance interpersonal communication. 2. In terms of project development, it is like a conservative who attaches importance to inheritance. Relatively speaking, it's conservative, nostalgic, lingering, elegant, social and line. It still retains the original British royal dance style, but there is innovation on this basis. When dancing, it not only requires embodying the noble elegance of Europeans, but also requires the Latino people to be playful and lively, and the legs and toes should have the elements of ballet [5]. The WDC reviewer believes that if there is no cultural precipitation, no ideological sparks, and the dance that jumps out is not vital. The true dance should be the dancer's exhalation through body language, facial expressions and the emotions of the dancers. For the WDSF dancers, the WDC reviewer judges that they are not dancing, just present high skills with superior difficulty. They do not understand emotional expression and the role of cultural heritage in dance.

WDSF's development philosophy: 1. Promote sports dance by entering the Olympics and thus making this niche project a well-known and well-loved sport. 2. In the development of the project, it is an innovative party that emphasizes innovation and boldly advances. Relatively speaking, they focus on speed, strength, force, innovation, fashion, competition, and keep pace with the times. In the dance choreography, the motion should be novel with emphasis on the competitive nature of sports dance, thus fully embodying sports dance as a sports project. Therefore, in the dance, emphasis is placed on factors such as speed, strength, endurance, explosiveness, and flexibility.

In terms of the development concept of the two, the author believes that both WDC and WDSF hope that the project will allow more people to participate, increase influence, and make a niche project become a public project. For the question that dance should be based on artistry or sports, we can fully integrate development. With the advancement of the times, sports dance must be constantly changing with the times. We cannot make the project slow to promote in afraid of the loss of the right to speak. The mainstream of today's social development is innovation, and sports dance should be like this. Therefore, WDC and WDSF have unified in promoting the project, maintained the traditional dance elements, and increased the sense of innovation, thus forming a unique new development concept.

\section{SUMMARY}

(1) The integration and development of WDC and WDSF requires the government to mediate and provide relevant support, so that the two associations can be combined into one.

(2) The integration and development of WDC and WDSF needs to start from dancer demands, establish a complete and unified teaching system, and form a unified teaching material, so that dancers have confidence in the project.

(3) The integration and development of WDC and WDSF needs to proceed from the judging rules, and the same indicators can be merged and the different can be combined and developed. This effectively avoids the subjectivity of WDC, and the stereotype of WDSF, thus making the sports dance evaluation rules innovate.

(4) In the development concept of the integration and development of WDC and WDSF, the sense of innovation should be poured into the traditional dance elements to form a new concept.

\section{ACKNOWLEDGMENT}

Address: No. 1 Bei'an Road, Shizhong District, Zaozhuang, Shandong, zip code 271600 Mailbox: 1026846140@qq.com mobile phone: 17863261118 QQ: 1026846140 .

\section{REFERENCES}

[1] Sun Lihong. Research on the Differences of the Code of Points of Competition between WDC and WDSF[D]. Master's thesis of Chengdu Sports Institute, 2016-06-08. (In Chinese)

[2] Sun Lihong. Research on the Differences of the Code of Points of Competition between WDC and WDSF[D]. Master's thesis of Chengdu Sports Institute, 2016-06-08. (In Chinese)

[3] Li Yuwei. The Evolution of the World Sports dance Federation (WDSF) competition rules [D]. The master's thesis of Beijing Sport University, 2015-06-02. (In Chinese)

[4] Liu Hu. Change Characteristics of WDSF Dance Sport Scoring System and its Influence on the Motion Techniques of World Elite Latin Dancers[D]. Master's thesis of Sichuan Normal University, 2016. (In Chinese)

[5] Jiang Jiafeng. Research on the development of "standardization" of international standard ballroom dancing $[\mathrm{J}]$. Journal of Zhejiang Vocational Academy of Art, 2017. (In Chinese) 